\title{
Schneiderian Membrane and Its Significance in Oral Implants
}

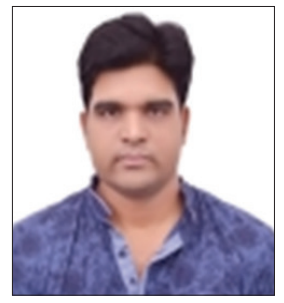

The maxillary sinus a pyramid-shaped cavity and largest paranasal air-filled space with a min volume of $12.5 \mathrm{ML}$. The Schneiderian membrane is also called as Schneiderian epithelium, which is a membranous lining that covers the inner part of the maxillary sinus. Nowadays, rehabilitation by prosthetic implants, even in edentulous areas of the maxilla affected by severe bone atrophies, is an unavoidable necessity, leading to the development of standardized, predictable, and safe regenerative techniques. The raising of the maxillary sinus is a surgical technique that vertically raises the usable volume of bone in the lateral-posterior areas of the maxilla, allowing.

This technique offers an outstanding opportunity for overcoming the bone atrophies correlate with edentulism, due in particular to the adequate signs from the literature..$^{[1-4]}$

Perforating the Schneiderian membrane during external sinus augmentation is well described and is most likely to occur at sharp angles and ridgelines, septa, and spines. ${ }^{[4]}$ Other problems in the literature associated with membrane

\begin{tabular}{|c|c|}
\hline \multicolumn{2}{|c|}{ Access this article online } \\
\hline Publisher & \multirow{2}{*}{$\begin{array}{l}\text { Website: } \\
\text { www.ijdms.in }\end{array}$} \\
\hline & \\
\hline & DOI: 10.30954/IJDMS.1.2020.1 \\
\hline
\end{tabular}

perforation are the development of mucoceles, chronic sinusitis, oroantral fistula, loss of graft material, and implants it without osseointegration.

\section{REFERENCES}

1. Testori T. Maxillary sinus surgery: Anatomy and advanced diagnostic imaging. J Implant Reconstr Dent 2011;2:6-14.

2. Sargi ZB, Casiano RR. Surgical anatomy of the paranasal sinuses. In: Kountakis SE, Onerci TM, editors. Rhinologic and Sleep Apnea Surgical Techniques. New York: Springer; 2007. p. 17-26.

3. Esposito M, Grusovin MG, Rees J, Karasoulos D, Felice P, Alissa R, et al. Effectiveness of sinus lift procedures for dental implant rehabilitation: A cochrane systematic review. Eur J Oral Implantol 2010;3:7-26.

4. Pignataro M, Mantovani M, Torretta S, Felisati G, Sambataro G. ENT assessment in the integrated management of candidate for (maxillary) sinus lift. Acta Otorhinolaryngol Ital 2008;28:110-9.

Anand Kumar

Department of Dentistry, Moti Lal Nehru Medical College, Prayagraj, Uttar Pradesh, India

Address for Correspondence:

Dr. Anand Kumar,

Department of Dentistry,

Moti Lal Nehru Medical College, Prayagraj,

Uttar Pradesh, India.

E-mail: anandkmr901@gmail.com

How to cite this article: Kumar A. Schneiderian Membrane and Its Significance in Oral Implants. Int J Dent Med Spec 2020;7(1):1.

Source of Support: None; Conflict of Interest: None 